\author{
연속 발진 다이오드 레이저로 여기된

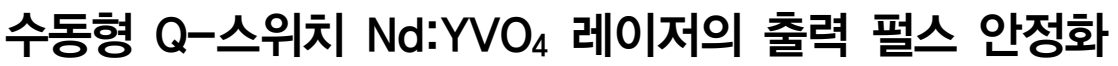 \\ 안승인 · 박윤배 \\ 경북대학교 과학교육학과 \\ (9) 702-701 대구광역시 북구 산격동 1370 번지 \\ 여환섭 · 이준호 \\ 경산과학고등학교 \\ (ㅇ) 712-260 경북 경산시 갑제동 440-6번지 \\ 이강인 · 이종훈 ${ }^{\dagger}$ \\ 영남대학교 물리학과 \\ (9) 712-749 경북 경산시 대동 214-1번지
}

(2009년 9월 7일 받음, 2009년 9월 30일 수정본 받음, 2009년 9월 30일 게재 확정)

$\mathrm{Cr}: \mathrm{YAG}$ 결정을 포화흡수체로 사용하여 수동형 Q-스위치시킨 다이오드 레이저 여기 $\mathrm{Nd}: \mathrm{YVO}_{4}$ 레이저를 제작하였다. Cr:YAG 결정의 한 면에 여기 빛 파장 $(808 \mathrm{~nm})$ 에 대해 고반사 코팅을 한 후, $\mathrm{Nd}: \mathrm{YVO}_{4}$ 결정과 접촉시켜 공진기를 구성하였다. $\mathrm{Cr}: \mathrm{YAG}$ 의 한 면에 여기 다이오드 레이저를 반사시키는 코팅을 입혀 공진기의 광변환 효율을 높임과 동시에, 여기빔에 의한 포화흡수체의 표백현상을 방지하여 안정된 출력이 나오게 하였다. 레이저 이득 매질 및 포화흡수체의 온도는 열전 냉각기와 냉각수를 사용하여 안정화 시켰다. 온도안정화를 시킨 상태에서 발진되는 펄스의 첨두 출력 요동(peak to peak)은 $4 \%$ 였다. 다이오드 레이저의 출력 이 $1 \mathrm{~W}$ 일 때, 출력 펄스의 반복률은 평균 $9 \mathrm{KHz}$ 였으며, 최소 펄스폭은 $7.11 \mathrm{~ns}$, 최고 출력은 $16.27 \mathrm{~mW}$ 였다.

\title{
Stabilization of Output Pulses from a Passively Q-switched Nd:YVO Laser Pumped by a Continuous-wave Laser Diode
}

\author{
Seungin Ahn and Yunebae Park \\ Department of Science Education, Kyungpook National University, 1370 Sankyuk-dong, Buk-gu, Deagu 702-701, Korea \\ Hwanseop Yeo and Joonho Lee \\ Gyeongsan Science High School 440-6 Gabje-dong, Gyeongsan 712-749, Korea \\ Kangin Lee and Jonghoon $\mathrm{Yi}^{\dagger}$ \\ Department of Physics, Yeungnam University, 214-1 Dae-dong, Gyeongsan 712-749, Korea \\ ${ }^{\dagger}$ E-mail:jhyi@yu.ac.kr
}

(Received September 7, 2009; Revised manuscript September 30, 2009; Accepted September 30, 2009)

\begin{abstract}
A Cr:YAG crystal was used as a saturable absorber for passive Q-switching of a $\mathrm{Nd}: \mathrm{YVO}_{4}$ laser which was pumped by a 1-W continuous wave laser diode. The first surface of the Cr:YAG was high-reflection coated for the pump wavelength. The high-reflection coating improved the absorption efficiency of the pump beam in the $\mathrm{Nd}: \mathrm{YVO}_{4}$ through double pass absorption. It also prevented pump beam induced partial bleaching of the Cr:YAG. The peak-to-peak pulse fluctuation of passively Q-switched laser output was approximately $4 \%$. The minimum pulse-width was measured to be $7.11 \mathrm{~ns}$. Also, the average pulse repetition rate was $9 \mathrm{kHz}$ and the maximum output power was $16.27 \mathrm{~mW}$.
\end{abstract}

${ }^{\dagger}$ E-mail: jhyi@yu.ac.kr 
Keywords: Passive Q-switching, Pulsed laser, Diode-pumped, Solid-state laser, Cr:YAG

OCIS codes: (140.3480) Lasers, diode-pumped; (140.3540) Lasers, Q-switched; (140.3538) Lasers, pulsed; (140.2020) Diode lasers

\section{I. 서 론}

수동형 Q-스위칭 레이저는 구조가 단순하고, Q-스위칭을 위해 외부의 전원장치가 필요 없는 장점이 있다. ${ }^{[-3]}$ 또한, 공 진기 길이를 짧게 하면 나노 초 이하의 펄스 출력이 가능하 며, 공진기 내부의 포화흡수체가 작은 개구(aperture) 역할을 하므로 출력 빔의 질이 우수하다. ${ }^{[4,5]}$ 하지만, 수동형 $\mathrm{Q}-$ 스위 칭 레이저는 출력의 요동이 심하여 응용의 확대에 걸림돌이 되고 있다. 포화흡수체로는 SESAM(semiconductor saturableabsorber mirror), $\mathrm{Cr}$ 도핑된 $\mathrm{YAG}$ 결정, 분자 빔 성장(MBE : molecular beam epitaxy)으로 $\mathrm{Cr}$ 박막을 표면에 입힌 $\mathrm{Nd}$ 또 는 $\mathrm{Yb}$ 로 도핑된 $\mathrm{YAG}, \mathrm{YVO}_{4}, \mathrm{KGd}\left(\mathrm{WO}_{4}\right)_{2}$ 결정 등을 고체레 이저 공진기에 삽입하거나 레이저 결정과 접합하여 구성 한다. ${ }^{[1]}$

최근 수년간 수동형 Q-스위칭 레이저의 펄스 출력 안정화 에 대한 연구가 지속적으로 진행되었으며 ${ }^{[6,7]}$, 최근 몇몇 그 룹에서 안정된 펄스 출력을 구한 결과를 보고하고 있다. 하 지만, 이들 방법에서는 외부 조절에 의한 펄스 여기 ${ }^{[6,7]}$, 공 진기 외부에 조절 광원을 두는 방법 ${ }^{[8]}$ 등을 사용하여 포화흡 수체 자체 $\mathrm{Q}-$ 스위칭에 대한 장점을 살리지 못하고, 광학계의 구조가 복잡하다.

본 연구에서는 출력이 $1 \mathrm{~W}$ 인 연속발진 $(\mathrm{CW})$ 레이저 다이

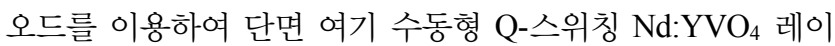
저를 제작하였다. 포화흡수체로는 $\mathrm{Cr}: \mathrm{YAG}$ 를 사용하였다. 먼 저, 양면에 $1064 \mathrm{~nm}$ 에 대하여 무반사 코팅이 된 $\mathrm{Cr}: \mathrm{YAG}$ 결 정을 사용하여 출력 특성을 측정하였다. 다음으로 포화흡수 체 앞면에 여기 다이오드 파장에 대해 전반사 코팅된 $\mathrm{Cr}: \mathrm{YAG}$ 를 이용하여 $\mathrm{Nd}: \mathrm{YVO}_{4}$ 결정에 인접하게 접촉시켜 공 진기를 구성하였다. Cr:YAG 결정의 앞면에서 여기빔을 반 사시킴으로 $\mathrm{Cr}: \mathrm{YAG}$ 에서 여기빔이 흡수되는 것에 의한 표백 현상을 방지하였다. 또한 여기빔이 $\mathrm{Nd}: \mathrm{YVO}_{4}$ 결정에 재흡수 되며, 두 결정 사이에 공간이 없어 공기 흐름에 따른 출력 손실도 방지되어 광변환 효율도 상승되었다. 여기빔 파장에 대해 한 면이 전반사 코팅된 $\mathrm{Cr}: \mathrm{YAG}$ 를 이용한 결과 안정된 펄스 출력을 얻었다. $\mathrm{Nd}: \mathrm{YVO}_{4}$ 와 $\mathrm{Cr}: \mathrm{YAG}$ 의 온도 안정화를 통해 출력 요동이 더욱 감소되었다.

\section{II. 실험 및 결과}

레이저의 구조는 그림 1 에 나와 있다. 이득 매질로 $3 \times 3 \times 1$ $\mathrm{mm}^{3}$ 크기의 1 at. $\% \mathrm{Nd}$ 를 도핑한 $\mathrm{YVO}_{4}$ 결정을 사용하였다. $\mathrm{Nd}: \mathrm{YVO}_{4}$ 의 앞면은 $1064 \mathrm{~nm}$ 레이저 빛에 대해 전반사, 808 $\mathrm{nm}$ 레이저 빛에 대해서는 투과율 $80 \%$ 이상이 되도록 이색 유전체 코팅을 하였으며, 뒷면은 $1064 \mathrm{~nm}$ 에 대하여 무반사 코팅을 하였다. $1 \mathrm{~W}$ 출력의 여기빔에 대해 $0.31 \mathrm{~W}$ 가 $\mathrm{YVO}_{4}$
결정을 투과하였으며, 이로부터 계산한 흡수계수는 $a$ $=1.17 / \mathrm{mm}$ 이었다. 포화흡수체는 크기가 $3 \times 3 \times 2 \mathrm{~mm}^{3}$ 이며, 초 기 투과율이 $80 \%$ 인 $\mathrm{Cr}: \mathrm{YAG}$ 를 이용하였다. $\mathrm{Cr}: \mathrm{YAG}$ 는 두가 지 종류를 사용하여 출력을 비교하였다. 먼저 그림 1(a)와 같 이 양면이 $1064 \mathrm{~nm}$ 레이저 빛에 대해 무반사 코팅된 $\mathrm{Cr}: \mathrm{YAG}$ 를 사용하여 출력을 측정하였다. 다음, 그림 1(b)와 같이 앞면은 $808 \mathrm{~nm}$ 레이저 빛을 반사하면서 동시에 1064 $\mathrm{nm}$ 레이저 빛에 대해 무반사하는 코팅이 되어있고, 뒷면은 $1064 \mathrm{~nm}$ 레이저에 대해 $68 \%$ 부분 반사하는 박막이 입혀진 $\mathrm{Cr}: \mathrm{YAG}$ 를 사용하였다. 이 $\mathrm{Cr}: \mathrm{YAG}$ 결정의 초기투과율도 80 $\%$ 이다. $\mathrm{Cr}: \mathrm{YAG}$ 는 $\mathrm{Nd}: \mathrm{YVO}_{4}$ 결정의 뒷면에 접촉하게 두었 다. 광검출 장치로는 실리콘 광다이오드(상승시간 $=1 \mathrm{ns,}$ DET 210, Thorlab사)를, 계측 장비로는 대역폭이 $300 \mathrm{MHz}$ 인 디지털 오실로스코프 (TDS3032, Tektronics사)를 사용하였다.

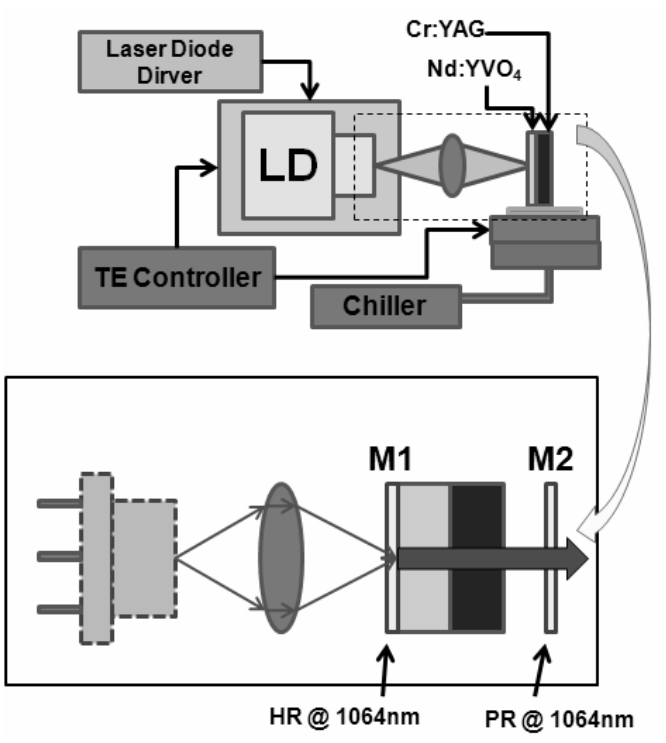

(a)

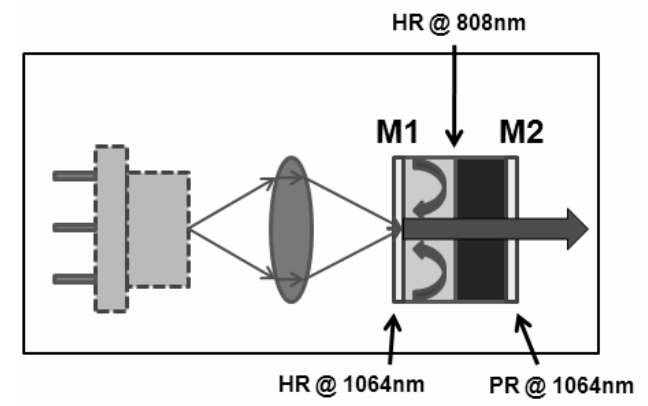

(b)

FIG. 1. Schematic diagram of a passively Q-switched $\mathrm{Nd}: \mathrm{YVO}_{4}$ laser and experimental setup. (a) cavity employing anti-reflection coated Cr:YAG crystal (cavity length $=12 \mathrm{~mm}$ ). (b) cavity employing high-reflection coated Cr:YAG crystal (cavity length $=3 \mathrm{~mm}$ ). 
인접한 $\mathrm{Nd}: \mathrm{YVO}_{4}$ 와 $\mathrm{Cr}: \mathrm{YAG}$ 결정은 얇은 인듐(indium) 금 속박으로 감싼 후 구리로 만든 마운트 내부에 삽입하여 고정 하였다. 이 구리 재질의 마운트 하단에는 냉각수 순환 장치 와 열전냉각기(thermoelectric cooler, TEC)를 장착하여 $\mathrm{Nd}: \mathrm{YVO}_{4}$ 와 $\mathrm{Cr}: \mathrm{YAG}$ 의 온도를 일정하게 유지 시켰다.

$\mathrm{Nd}: \mathrm{YVO}_{4}$ 를 여기하는 연속발진 다이오드(Sony, 파장=808 $\mathrm{nm}$ )는 $\mathrm{TO}$ 캔 형태를 가졌으며 최대 출력이 $1 \mathrm{~W}$ 이다. 다이오 드 레이저는 냉각장치가 일체화된 전용 마운트(Thorlab)에 장착되었으며, 마운트에 내장된 열전냉각기를 이용하여 온도 를 $21^{\circ} \mathrm{C}$ 로 유지하였다. 레이저 다이오드에서 나온 빔은 수직 방향으로 약 $30^{\circ}$, 수평 방향으로 약 $10^{\circ}$ 각도로 확산되며, 이 빔은 초점거리가 약 $10 \mathrm{~mm}$ 인 비구면 렌즈쌍(aspherics lens

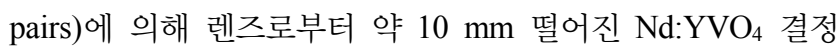
표면에 집속된다.

다이오드 레이저 빔에 의한 $\mathrm{Cr}: \mathrm{YAG}$ 의 부분 표백현상이

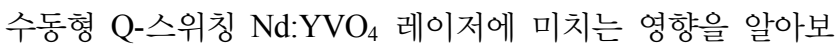
기 위하여, 먼저 무반사 코팅된 $\mathrm{Cr}: \mathrm{YAG}$ 를 사용한 레이저의 특성을 측정하였다. 레이저의 출력경은 출력경이 코팅된 $\mathrm{Cr}: Y A G$ 를 이용한 경우와 비교하기 위하여 반사율이 $75 \%$ 로 근접한 평면경을 사용하였고, 공진기의 길이는 $12 \mathrm{~mm}$ 이 다. $\mathrm{Nd}: \mathrm{YVO}_{4}$ 와 $\mathrm{Cr}: \mathrm{YAG}$ 의 온도를 $21^{\circ} \mathrm{C}$ 로 안정화 시킨 상태 에서, 레이저 다이오드의 출력이 $1 \mathrm{~W}$ 일 때 $\mathrm{Q}$-스위칭된 펄스 를 얻었다. 그림 2에서 보듯 레이저의 평균 출력은 $8.2 \mathrm{~mW}$ 이었으며, 펄스폭은 $29.3 \mathrm{ns,} \mathrm{펄스} \mathrm{반복률은} 407 \mathrm{kHz}$ 였다. 레 이저 펄스 첨두 출력의 요동은 약 $36 \%$ 이었다.

다음, 그림 1(b)와 같이 여기 파장의 레이저를 반사하는 코 팅이 된 $\mathrm{Cr}: \mathrm{YAG}$ 를 이용한 $\mathrm{Nd}: \mathrm{YVO}_{4}$ 레이저를 제작하였다. $\mathrm{Nd}: \mathrm{YVO}_{4}$ 와 Cr:YAG 경계면에 여기빔 반사 코팅을 하여, 경 계 면에서의 여기빔 반사를 통해 재흡수를 유도하고 광변환 효율의 증가와 여기빔에 의한 $\mathrm{Nd}: \mathrm{YVO}_{4}$ 결정의 열 분포를 고르게 하여 열에 의한 종모드 요동을 최소화하고자 시도하 였다. 그리고 포화흡수체로 흡수되는 여기빔을 감소시켜 여

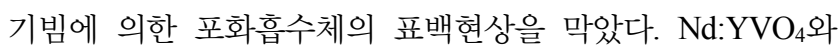

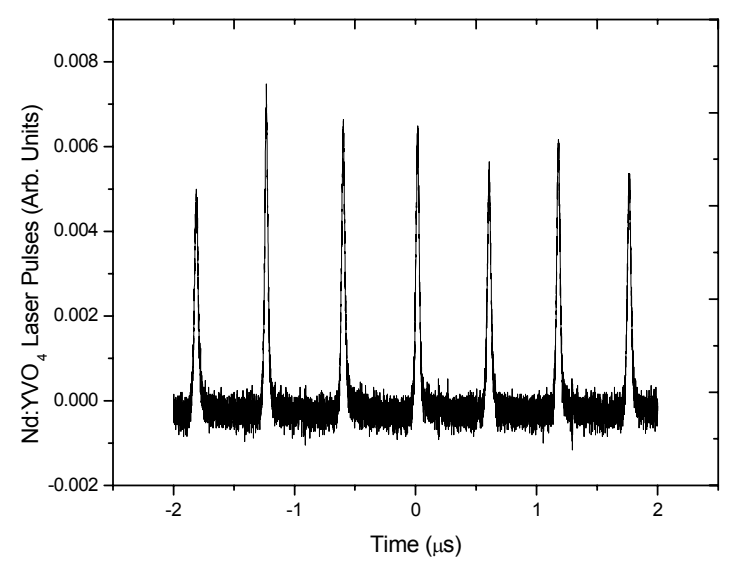

FIG. 2. Temporal profiles of passively Q-switched $\mathrm{Nd}: \mathrm{YVO}_{4}$ laser output pulses (laser diode output power $=1 \mathrm{~W}$, output coupler reflectance $=75 \%$, cavity length $=12 \mathrm{~mm}$ ).
$\mathrm{Cr}: Y A G$ 결정을 접촉하여 구성한 공진기 전체 길이는 $3 \mathrm{~mm}$ 이다. 두 결정의 온도를 $21^{\circ} \mathrm{C}$ 로 유지 시킨 후 여기빔의 출력

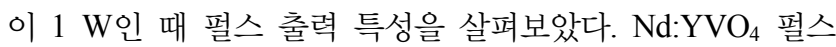
반복률과 출력 요동은 여기빔이 레이저 결정에 입사한 위치 에 따라 민감하게 변하였다. 펄스반복률이 $9 \mathrm{KHz}$ 내외가 되 면 요동이 감소하며 안정된 펄스출력을 보였다. 그림 3은 측 정 결과를 보여주며 펄스 시간폭은 $11.23 \mathrm{ns,} \mathrm{반복률은} 8.7$ $\mathrm{KHz}$ 이었다. 한 시간 동안 출력 변화를 측정한 결과, 출력 요동은 약 $4 \%$ 였다. 최고출력은 $14.3 \mathrm{~mW}$ 이며 광변환 효율이

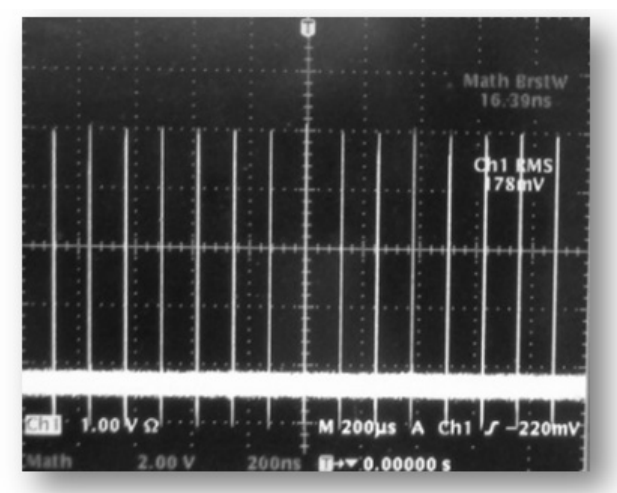

(a)

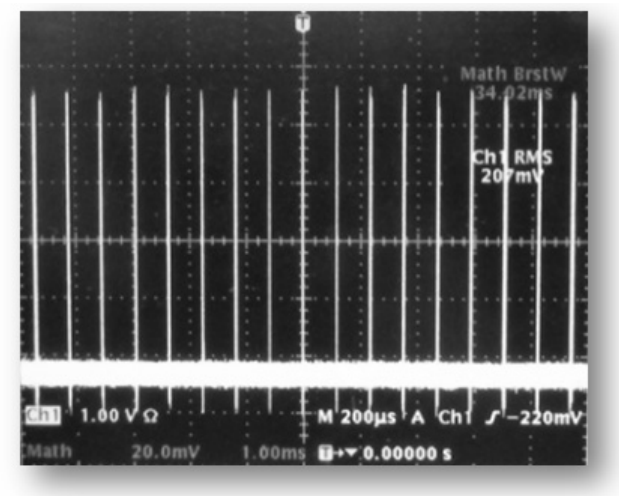

(b)

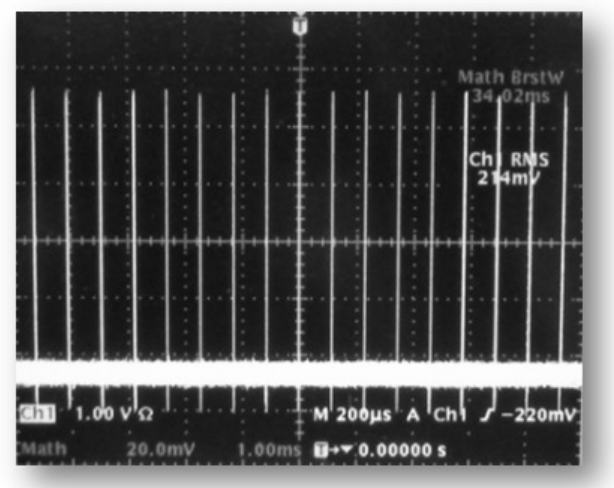

(c)

FIG. 3. The temporal profiles of passively Q-switched $\mathrm{Nd}: \mathrm{YVO}_{4}$ laser pulses as a function of the crystal temperature (laser diode output power $=1 \mathrm{~W}$, reflectance of output coupler = $68 \%$, cavity length $=3 \mathrm{~mm}$ ). (a) crystal temperature $=20^{\circ} \mathrm{C}$ (b) crystal temperature $=22^{\circ} \mathrm{C}$ (c) crystal temperature $=24^{\circ} \mathrm{C}$. 
$1.4 \%$ 로, 무반사 코팅된 $\mathrm{Cr}: \mathrm{YAG}$ 를 삽입하여 공기에 노출된 경우 보다 효율이 1.8 배 올라갔다. 레이저가 발진 문턱 근처 에서 발진하고 있으므로 투과한 $0.31 \mathrm{~W}$ 를 되반사하여 여기 에 사용하고, 공진기의 길이가 짧아서 손실이 감소하여 출력 이 상승하였다. 수동형 Q-스위칭에 사용된 $\mathrm{Cr}: \mathrm{YAG}$ 결정에 서의 흡수로 인하여 발진 효율이 감소하였으며, 본 연구에서 의 결과는 타 연구에서의 효율과 비슷하다. ${ }^{[4]}$

다이오드 레이저의 출력을 $1 \mathrm{~W}$ 로 고정시킨 후, 두 결정의 온도를 $18^{\circ} \mathrm{C}$ 에서 $30^{\circ} \mathrm{C}$ 로 $1^{\circ} \mathrm{C}$ 간격으로 바꾸어 가며 펄스 출 력 특성을 살펴보았다. 결정의 온도가 변하는 동안에는 펄스 출력은 요동하지만, 일정한 온도로 안정화된 이후에는 3 4 $\%$ 사이의 요동을 가진 안정된 펄스 출력을 보였다. 그림 4(a)에서 보듯 각 온도에 따라 수동형 Q-스위칭된 펄스 출력 세기가 조금씩 변하며, $25^{\circ} \mathrm{C}$ 에서 펄스 평균 최고 출력 16.27 $\mathrm{mW}$ 이었다. 펄스반복률은 온도에 따른 변화가 거의 없이 평균 $9 \mathrm{KHz}$ 정도였으며, $25^{\circ} \mathrm{C}$ 이후 펄스반복률이 감소하였 다. 출력 펄스 시간폭은 반복률 경우보다 온도에 따른 변화

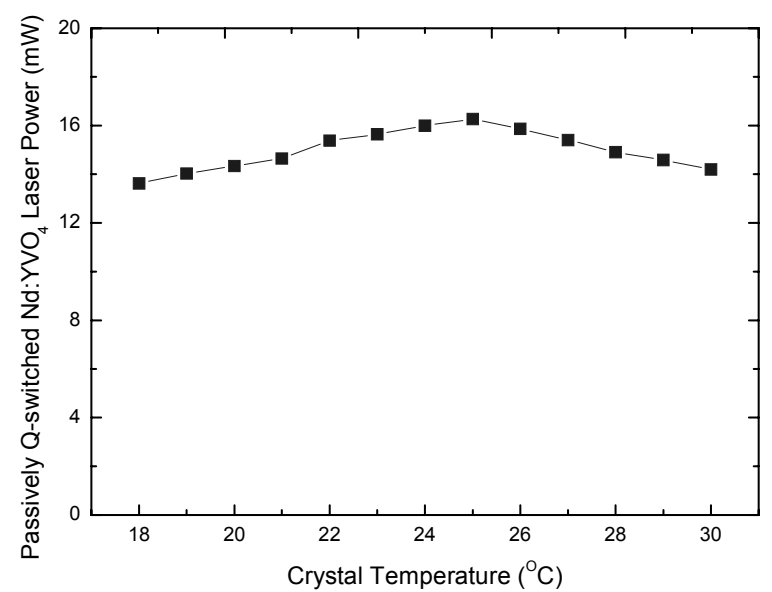

(a)

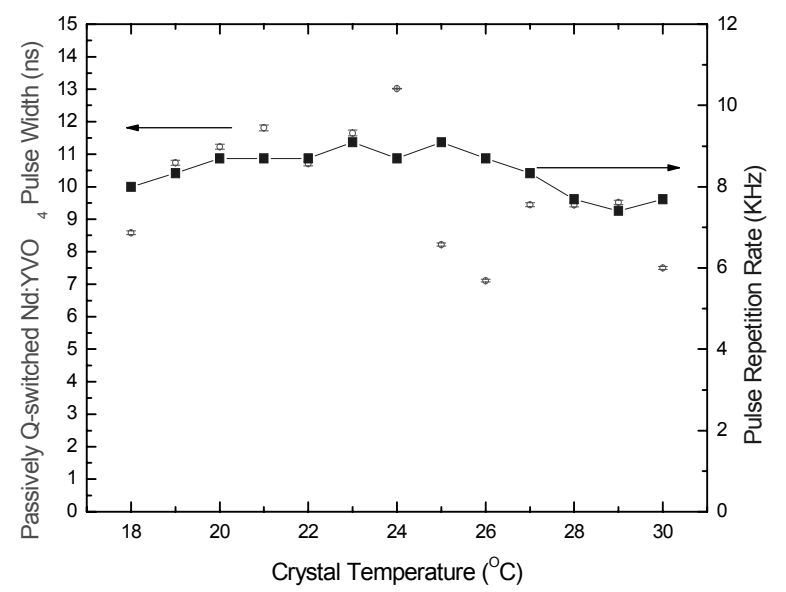

(b)

FIG. 4. The pulse characteristics as a function of the crystal temperature (laser diode output power $=1 \mathrm{~W}$, reflectance of output coupler $=68 \%$, cavity length $=3 \mathrm{~mm}$ ). (a) average output power (b) pulse width and pulse repetition rate.

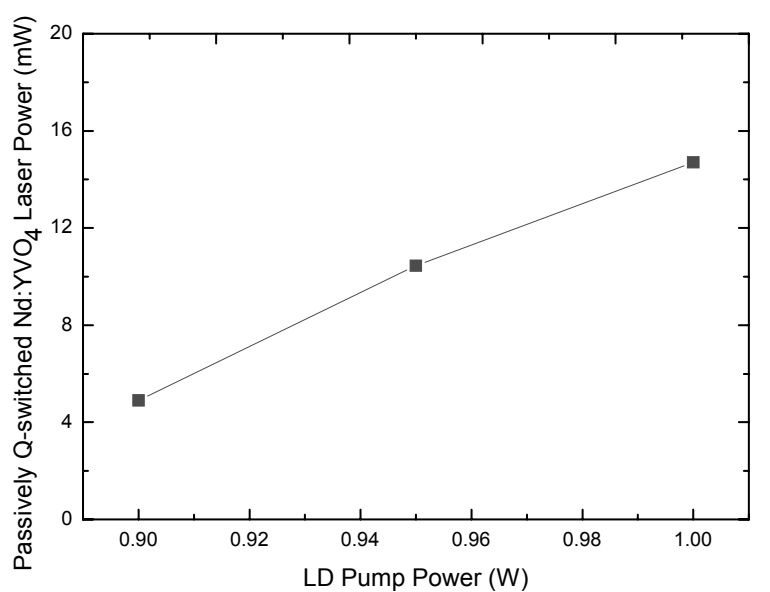

(a)

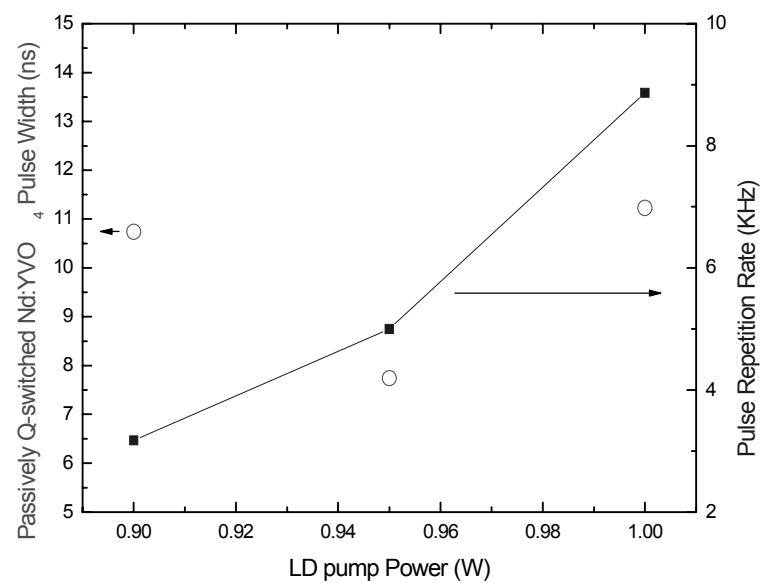

(b)

FIG. 5. The variation of the pulse characteristics as a function of the laser diode pump power (crystal temperature $=20^{\circ} \mathrm{C}$, reflectance of output coupler $=68 \%$, cavity length $=3$ $\mathrm{mm}$ ). (a) average output power (b) pulse width and pulse repetition rate.

가 크게 변하였다. 그림 $4(\mathrm{~b})$ 에서 보듯 $26^{\circ} \mathrm{C}$ 에서 $7.1 \mathrm{~ns}$ 의 가 장 짧은 펄스 시간폭을 보였다. 측정된 펄스폭의 경우 광검 출기가 포화되어 측정되어, 실제 펄스폭은 이보다 더 짧게 측정될 수 있다. 이 때 첨두 출력은 $0.21 \mathrm{MW}$ 이었다.

두 결정의 온도를 $20^{\circ} \mathrm{C}$ 로 고정시킨 후, 여기빔의 출력을 $0.05 \mathrm{~W}$ 씩 올려가며 레이저 다이오드 출력에 따른 펄스 출력 특성을 살펴보았다. 두 결정의 온도가 고정된 상태에서 여기 빔의 출력을 변화시킬 경우, 수동형 $\mathrm{Nd}: \mathrm{YVO}_{4}$ 레이저의 평균 출력만 변할 뿐, 펄스 출력 요동은 $4 \%$ 정도로 안정되었다. 출력경과 $\mathrm{Cr}: \mathrm{YAG}$ 사이의 공기 유동을 없애고, 여기 다이오 드 레이저가 $\mathrm{Cr}: \mathrm{YAG}$ 에 미치는 영향을 감소시킨 결과 요동 이 감소한 것으로 생각된다. 그림 5에서 보듯 여기빔의 출력 이 $0.9 \mathrm{~W}$ 일 때, 수동형 $\mathrm{Q}-$ 스위칭 $\mathrm{Nd}: \mathrm{YVO}_{4}$ 레이저가 발진하 였다. 이 때 레이저 평균 출력은 $4.9 \mathrm{~mW}$ 이었다. 여기빔 출 력을 증가시켜, $\mathrm{Nd}: \mathrm{YVO}_{4}$ 레이저의 출력도 높아졌다. 또한 펄스반복률도 여기빔 출력이 $0.9 \mathrm{~W}$ 일 때, $3.2 \mathrm{KHz}$ 로 가장 낮았지만, 출력이 올라감에 따라 $8.7 \mathrm{KHz}$ 까지 증가하였다. 


\section{III. 결 론}

레이저 다이오드로 단면 여기하는 수동형 Q-스위칭된 $\mathrm{Nd}: \mathrm{YVO}_{4}$ 레이저를 제작하였다. 공진기 내부에 $\mathrm{Cr}: \mathrm{YAG}$ 결 정을 두어 포화흡수체로 이용하였다. 먼저, 양면이 $1064 \mathrm{~nm}$ 에 대하여 무반사 코팅된 $\mathrm{Cr}: \mathrm{YAG}$ 를 사용한 공진기를 구성 하였다. 결정의 온도가 $21^{\circ} \mathrm{C}$ 이고 여기 다이오드 출력이 $1 \mathrm{~W}$ 일 때 출력은 $8.2 \mathrm{~mW}$ 이며, 펄스 출력 요동이 $36 \%$ 이었다.

$\mathrm{Nd}: \mathrm{YVO}_{4}$ 의 여기 효율을 올리고, 여기광에 의한 $\mathrm{Cr}: \mathrm{YAG}$ 의 표백 현상을 방지하기 위해 앞면은 여기 다이오드 레이저 파장 $(808 \mathrm{~nm})$ 에 대해 전반사 코팅을 하고, 뒷면은 공진 레이 저 파장 $(1064 \mathrm{~nm})$ 에 대해 부분반사 코팅된 $\mathrm{Cr}: \mathrm{YAG}$ 를 이용 하였다. 뒷면은 출력경으로 사용하여 출력경과 $\mathrm{Cr}: \mathrm{YAG}$ 결 정 사이의 공기 흐름에 의한 출력 변화를 감소시켰다. 결정 의 온도가 $21^{\circ} \mathrm{C}$ 이고 여기 레이저 출력이 $1 \mathrm{~W}$ 일 때 Q-스위 칭된 레이저 출력은 $14.3 \mathrm{~mW}$ 이었으며, 결정의 온도가 $25^{\circ} \mathrm{C}$ 에서 최고 레이저 출력 $16.27 \mathrm{~mW}$ 얻었다. 여기 레이저의 반 사와 함께 결정의 온도를 안정화시켜서 출력 요동을 약 $4 \%$ 정도로 감소시켰다.

\section{감사의 글}

본 연구는 2009학년도 경상북도교육청(미래과학자양성프 로그램) 지원으로 수행되었음.

\section{References}

1. J. Dong, K.-I. Ueda, Y. Hideki, and A. A. Kaminskii,
"Laser-diode pumped self-Q-switched microchip lasers," Optical Review 15, 57-74 (2008).

2. J. Li, J. Dong, M. Mitsurua, A. Shirakawa, and K.-I. Ueda, "Transient temperature profile in the gain medium of CWand end-pumped passively Q-switched microchip laser," Opt. Comm. 270, 63-67 (2002).

3. Y. Kalisky, C. Labbe, K. Waichman, L. Kravchik, U. Rachum, P. Deng, J. Xu, J. Dong, and W. Chen, "Passively Q-switched diode-pumped Yb:YAG laser using Cr4+-doped garnets," Optical Materials 19, 403-413 (2002).

4. Y. Kalisky, "Cr4 $4^{+}$-doped crystals: their use as lasers and passive Q-switches," Progress in Quangtum Electronics 28, 249-303 (2004).

5. N. Pavel, J. Saikawa, S. Kurimura, and T. Taira, "High average power diode end-pumped composite Nd:YAG laser passively Q-switched by Cr4+:YAG saturable absorber," Jpn. J. Appl. Phys. 40, 1253-1259 (2001).

6. M. Tsunekne, T. Inohara, A. Ando, K. Kanehara, and T. Taira, "High peak power, passively Q-switched Cr:YAG/ Nd:YAG micro-laser for ignition of engine, “ in Proc. Advanced Solid-State Photonics (Nara, Japan, Jan. 2008), MB4.

7. M. Tsunekne, T. Inohara, A. Ando, K. Kanehara, and T. Taira, "Compact, high peak power, passively Q-switched micro-laser for ignition of engines," in Proc. CLEO/QELS (San Jose, California, USA, May 2008), CFJ4.

8. B. Cole, L. Goldberg, C. W. Trussell, A. Hays, B. W. Schilling, and C. McIntosh, "Reduction of timing jitter in a Q-switched Nd:YAG laser by direct bleaching of a $\mathrm{Cr}^{+}$:YAG saturable absorber," Opt. Exp. 17, 1766-1771 (2009). 